Aerospace Science and Technology, Volume 87, April 2019, Pages 300-310

DOI: $10.1016 /$ j.ast.2019.02.025

\title{
MULTI-BLADE SHEDDING IN TURBINES WITH DIFFERENT CASING AND BLADE TIP ARCHITECTURES
}

\section{Ibrahim Eryilmaz}

School of Aerospace, Transport and Manufacturing, Cranfield University, Bedfordshire, UK

\section{Biläl Guenchi}

School of Aerospace, Transport and Manufacturing, Cranfield University, Bedfordshire, UK

\section{Vassilios Pachidis}

School of Aerospace, Transport and Manufacturing, Cranfield University, Bedfordshire, UK

\section{ABSTRACT}

A shaft failure in a gas turbine engine results in the decoupling of the turbine and the compressor. The turbine continues extracting work from the air flow causing the acceleration of the free-running turbine which can result in debris release or even disc burst. Post shaft failure the structural integrity of the engine must be guaranteed for product safety and certification purposes. To achieve this, speed limiting systems have to be integrated. One common method is friction between the rotor and stationary structures which occurs during unlocated failures where the bearing arrangement allows axial movement of the rotor under end load. Another possible mechanism is the destruction of the turbine rotor blades such that they cease to extract power from the incoming flow, decelerating progressively. Blade shedding involves rupture of blades which may result in their containment within the casing or rupture of the turbine casing. This research investigates the effects of excessive damage as blades rupture in the high-pressure turbine of a large civil engine. The research investigates different casing inclinations and shrouded/unshrouded blade configurations respectively. The nonlinear finite element software LS-DYNA is used to model 
two blade release scenarios which are; i) simultaneous release of all blades, and ii) simultaneous sectoral release of blades. The blades are released from firtrees considering the worst case scenario from a containment point of view. It is observed that a sector having a sufficient number of blades can result in the same effect caused by all blades impacting the casing. Containment requirements of shrouded and unshrouded rotors with different casing inclinations are compared as a function of the blade kinetic energy. Provided that the blade mass is kept constant, the effect of the casing inclination is found to be dominant when compared to the effect of blade tip geometry. Together with a rotor overspeed trajectory, the containment requirement of a simultaneous multiblade shedding application for disk burst prevention is given. The research provides improved understanding of blade tip-to-casing interactions, to be used as an overspeed prevention mechanism, and contributes towards developing design guidelines for the next generation of aero engines in terms of fail-safe engine architectures.

Keywords: shaft failure; turbine overspeed; blade rupture; LS-DYNA; finite element analysis

\section{NOMENCLATURE}
A Johnson-Cook stress parameter
B Johnson-Cook strain hardening parameter
C Specific heat
D Johnson-Cook damage parameter
E Energy, Elastic modulus
$\mathrm{K} \quad$ Experimental constant
KE Kinetic energy
L Length
LSL Long shot line
P Pressure 


\begin{tabular}{ll} 
T & Torque \\
V & Containment equation angle correction factor \\
X & Containment equation blade count factor \\
Y & Containment equation blade count factor \\
C & Johnson-Cook strain rate parameter \\
e & Exponential \\
eff & Effective \\
h & Height \\
m & Johnson-Cook thermal exponent \\
n & Johnson-Cook strain hardening exponent \\
p & plastic \\
t & Thickness \\
a & Casing inclination \\
$\varepsilon$ & Strain \\
$\dot{\varepsilon}$ & Strain rate \\
$\varepsilon$ & Reference strain rate \\
$\theta$ & Johnson-Cook temperature ratio \\
$\sigma$ & Stress \\
$\rho$ & Density \\
H & Friction coefficient \\
$\#$ & Blade count \\
\hline
\end{tabular}

\section{INTRODUCTION}

Gas turbine technology has experienced a significant amount of development over recent decades. In the aerospace industry, the main objectives of an engine designer are the improvements of efficiency and thrust to weight ratio which are indicators of engine performance. To do so, modern engines operate with higher temperatures and pressures, and therefore, they are 
subjected to higher stresses. In this more arduous environment, engine manufacturers have to guarantee the structural integrity of critical parts of the engine during the design and certification processes.

This study aims to investigate the effects of excessive damage as turbine blades rupture with different casing and blade tip architectures for a civil large engine. After a review of high energy impact and perforation, two scenarios are studied i.e. the simultaneous release of all blades, and the release of a sector of blades. Containment requirements are evaluated considering different casing inclinations and blade tip geometries. The non-linear finite element software LS-DYNA is used to model the impact scenarios and draw useful conclusions on blade containment regarding the effects of normal and oblique impacts as well as blade tip geometry.

Parameters relevant to fan blade casing containment are given by Lane [1] as kinetic energy of the blades; geometry of the blades as thickness, chord length, and span; and strength of the containment structure. Lane [1] also described two distinct types of failure and containment. The first type is associated with the release of disk fragments after the burst and characterized by large plastic deformation followed by tensile failure. The recommended containment material for this type of failure should allow large plastic elongation before tensile failure. Inconel 625 is given as an example for the hot turbine sections. The second type is associated with the blades penetrating through a localized hole. For this type, the use of hard materials like ceramics in the hot section which can deform and break the blade on impact is recommended. Ceramics in combination with less temperature resistant polymer fibers is also proposed for further weight efficient solutions.

According to Dewhurst [2], for the case of disk fragments after a burst, two stages of failures can be identified. In the first step, named stage one, the fragments perforate the casing by punching out a segment. If the casing withstands this impact, stage two will occur whereby the fragments pressurize the ring to create large tangential stresses. Dewhurst [2] stated that similar to the disk fragments, the mass of the blade fragments in the case of a multiple blade shed can create very high tangential stresses causing the failure of the containment ring after the successful prevention of the stage one type failure. 
He et al. [3] characterized the single blade impact phenomena in three stages. During the first stage, the released blade scratches the containment ring inner area; during the second phase the blade changes its orientation, and contact occurs in a long and narrow area. A bulge forms at this stage along with cracking of the casing. At the third stage the casing tears. The main energy absorption of the casing is defined as the bulging crack induced by bi-axial tension during the second phase. This scenario can be classified as an example to the successful prevention of stage one of Dewhurst [2] definition and failure at stage two.

Since the scope of the current study is related to the sectoral or whole blade release at the turbine hot section, both types of the containment ring failure are relevant. These are the localized failure of the ring by a single blade and the mostly tensile failure of the ring under the force generated by a number of blades. Various design and modelling approaches are active topics in engine design to minimise the undesired consequences of component failures by making them more predictable and controllable.

Kraus and Frischbier [4] at MTU Aero Engines modelled blade loss in a low-pressure turbine which has an inner liner and an outer turbine exhaust casing. Additional to the $7 \mathrm{~mm}$ original thickness they used two other containment thicknesses as $5 \mathrm{~mm}$ and $3.6 \mathrm{~mm}$. A fully integrated solid element formulation was used to avoid hourglassing in the LS-DYNA simulations. The blade was released above the outermost firtree including blade shroud, blade, and the shank platform. The LSDYNA eroding surface to surface contact was defined between parts without friction due to unknown friction coefficients.

Hermosilla et al. [5] modelled blade to casing impact of the Trent 900 low-pressure turbine. The blade was modelled as rigid, and they evaluated two alternative casing designs by shell elements. The same containment capacity was obtained by lightening the constant thickness casing by use of cross stiffeners. The stiffeners absorbed higher load by axial stress as the straight casing provided absorption mainly due to shell bending.

A single fan blade impact orientation study was done by Carney et al. [6]. The casing impact region was curved for an experimental and numerical study. According to the observations, a $45^{\circ}$ 
impact orientation improved the containment capability in the order of $60 \mathrm{~m} / \mathrm{s}$ with respect to a normal impact. Assuming the impact speed is in the order of $400 \mathrm{~m} / \mathrm{s}$, typical fan tip speed, the oblique casing results in a $15 \%$ speed containment improvement.

Further to the modelling of the blade and casing interactions, examples of releasing blades in a controlled manner have been reported to prevent hazardous conditions after failures. Seinturier [7] reported a fuse system which relies on releasing all the blades at a given speed in a Turbomeca turboshaft second stage power turbine, during a shaft overspeed. This method is used to avoid disk burst which is hard to contain.

Multi-blade shedding can occur in the case of an unlocated shaft failure to prevent the burst of the overspeeding disk. Soupizon [8] proposed a stationary cutter platform in a Snecma lowpressure turbine which is assembled downstream of the turbine blades. The cutter is oversized to be strong and designed to cut a portion of struts below the blade root. With the effect of high centrifugal forces, the blades are released to protect the disk.

Within the scope of the modelling and design alternatives presented herein, after the verification of the LS-DYNA simulations against impact experiments, several blade and casing configurations are studied regarding the containment thickness requirement. The obtained design equations are to be used in future sizing studies to scale the containment requirement as a function of the studied parameters in this research. The overspeed design space generated for a blade shedding scenario, as an overspeed prevention method for located and unlocated failures, provides guidelines on component design.

\section{METHODOLOGY}

Among different rotor and casing designs, blades with straight shrouds, i.e zero hade angles, provide better tip gap control, however they are prone to suffer from leakage of hot gas to disk cavities from the inclined hub when the turbine moves axially. On the other hand, blades with inclined shrouds suffer from losses, and straight hubs provide better sealing during axial movements. The shrouded blades of a low-pressure turbine with straight and approximately $35^{\circ}$ 
inclined casings are discussed by Adams et al. [9]. In these types of conventional shrouded blades, the shrouds of the adjacent blades are in contact. A squealer tip turbine blade for a high-pressure turbine is given by Stec et al. [10]. These kinds of blades do not have conventional shrouds, and they do not touch one another.

According to the mentioned architectures above, the geometry of a turbine stage is modified with an unshrouded straight tip, unshrouded inclined tip and shrouded configuration. To investigate the containment requirements of simultaneous multi-blade shedding in different configurations, the inner liner casing also containing the abradable honeycomb structures are assumed to be solid having the same material of the blades. A summary of the design space is given in Figure 1. In Model A, a straight blade impacts a straight casing. Then, in Model B and Model C the effect of the casing inclination is investigated: therefore the casing is inclined at angles of $20^{\circ}$ to $40^{\circ}$. In Model B, Model D, and Model E, the effect of blade tip is investigated with the same casing.


Figure 1. Blade tip and casing configurations

According to Hagg and Sankey [11], containment is possible if the kinetic energy of the fragments is smaller than the energy which is required to plastically strain the containment shield in compression and shear. The condition is given by Equation (1). Lane [1] provided the thickness as a function projectile kinetic energy and a lumped $\mathrm{K}$ parameter by Equation (2). $\mathrm{K}$ is an empirical constant, which differs from one engine manufacturer to another according to the materials used. 
However, it is expected to be high for conditions where high strength or rigid blades impact the casing and expected to be low where the casing has higher strength than the blades.

$$
\begin{gathered}
\mathrm{E}_{\text {compression }}+\mathrm{E}_{\text {shear }}>\mathrm{E}_{\text {fragment }} \\
\mathrm{t}=\mathrm{K} \cdot \sqrt{\mathrm{KE}}
\end{gathered}
$$

Piekutowski et al. [12] studied the impact of a steel bullet on a flat aluminium plate. The projectiles were launched at striking velocities, or initial velocities, up to $750 \mathrm{~m} / \mathrm{s}$. The $67.5 \mathrm{~mm}$ projectile has a mass of 81 grams. Considering a $400 \mathrm{~m} / \mathrm{s}$ gas turbine blade speed, the projectile velocities cover a range from nominal speed to burst conditions up to $200 \%$ of rotor speed. Since the mass and dimensions of the projectile are representative of a turbine blade and the projectile velocities cover a wide range of speeds, the experiment fits to the objective of our study for the method verification of containment analysis in an overspeeding turbine. The finite element methodology of the current study using the LS-DYNA finite element software is verified against the impacts with a comparison against the experimental results of a projectile impacting to a target plate. 


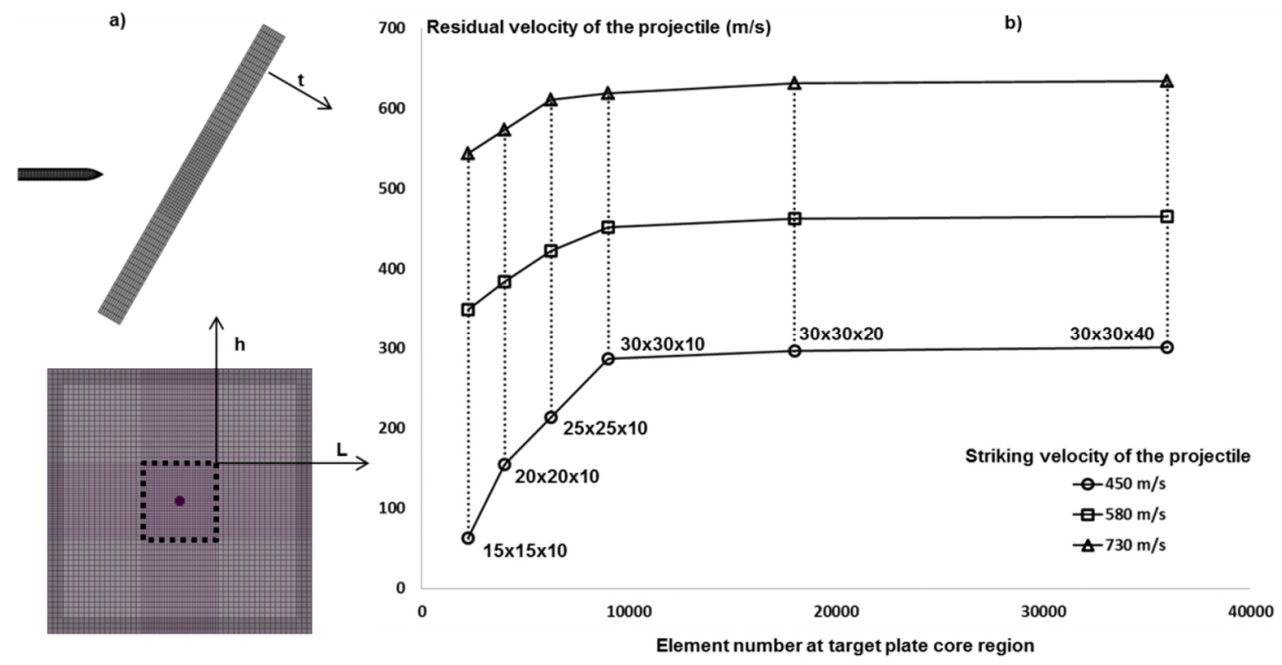

Figure 2. a) Finite element model of the experiment b) Mesh density effect on the results

In the LS-DYNA model, a constant thermal load at room temperature is applied to all parts and an initial velocity is defined to the projectile. Fully integrated solid elements are used, and the Johnson-Cook material model is assigned to both the impactor and the target. The projectile has 10000 solid elements and is launched to impact the target plate at an angle of 30 degrees. The finite element model is given in Figure 2a. The target plate has a fine mesh at the core region, given with dashed lines. This meshing strategy is used to save computational time. Several mesh densities for the target plate are used in the h-L-t directions. The residual velocity of the projectile is plotted as a function of the target plate core region element number in Figure $2 b$ at different projectile striking velocities. The residual velocity is found to be changing as a function of the model element density. The results tend to converge slightly after the target plate core region element number $30 \times 30 \times 10$ in the h-L-t directions. This is more visible in the $450 \mathrm{~m} / \mathrm{s}$ convergence behaviour. This mesh size results in an overall agreement with the experiment and the maximum error with respect to the experiment drops to $4 \%$ at $30 \times 30 \times 10$ mesh density and is seen at a striking velocity of $730 \mathrm{~m} / \mathrm{s}$. However, the simulations are also influenced by rate effects, friction coefficient and the element formulation. 
The Johnson-Cook [13] material model includes a constitutive and a failure model. The constitutive model scales the yield strength and defines material plasticity as a function of strain rate and temperature. The failure model defines the failure strain of the material as a function of stress triaxiality, strain rate and temperature. The stress triaxiality is defined as the ratio of element hydrostatic stress to equivalent stress. The Johnson-Cook constitutive model is described in Equation 3 with the temperature dependence term in Equation 4. The failure model is defined in Equation 5 where the triaxiality term is given as a product with the $D_{3}$ parameter.

$$
\begin{gathered}
\sigma=\left[\mathrm{A}+\mathrm{B} \cdot \epsilon_{\mathrm{p}}^{\mathrm{n}}\right] \cdot\left[1-\theta^{\mathrm{m}}\right] \cdot\left[1+\mathrm{C} \cdot \ln \frac{\dot{\varepsilon}}{\varepsilon_{0}}\right] \\
\theta^{\mathrm{m}}=\frac{\mathrm{T}-\mathrm{T}_{\text {room }}}{\mathrm{T}_{\text {melt }}-\mathrm{T}_{\text {room }}} \\
\varepsilon_{\text {failure }}=\left[\mathrm{D}_{1}+\mathrm{D}_{2} \cdot \mathrm{e}^{\left(\mathrm{D}_{3} \cdot \frac{\mathrm{P}}{\sigma_{\text {eff }}}\right)}\right] \cdot\left[1+\mathrm{D}_{4} \cdot \ln \frac{\dot{\varepsilon}}{\varepsilon_{0}}\right] \cdot\left[1+\mathrm{D}_{5} \cdot \theta\right]
\end{gathered}
$$

\begin{tabular}{|c|c|c|c|c|c|}
\hline & Elastic properties & & & & \\
\hline & $E(G P a)$ & $\rho\left(\mathrm{kg} / \mathrm{m}^{3}\right)$ & $\mathbf{v}$ & $\underset{(\mathrm{J} / \mathrm{kg} \cdot \mathrm{K})}{\mathrm{C}}$ & \\
\hline Projectile [13][14] & 200 & 7830 & 0.29 & 477 & \\
\hline \multirow[t]{3}{*}{ Target Plate [13][17] } & 69 & 2703 & 0.33 & 917 & \\
\hline & Constitutive model & & & & \\
\hline & $\mathrm{A}(\mathrm{MPa})$ & $\mathrm{B}(\mathrm{MPa})$ & $\mathbf{n}$ & $\mathbf{m}$ & $\varepsilon_{0}(1 / s)$ \\
\hline Projectile [13][14][15] & 1430 & 1250 & 0.65 & 1 & 1 \\
\hline \multirow[t]{3}{*}{ Target Plate [13][18][19][20] } & 262 & 154 & 0.23 & 1 & 1 \\
\hline & Failure model & & & & \\
\hline & $\mathbf{D}_{1}$ & $\mathrm{D}_{2}$ & $\mathbf{D}_{3}$ & $\mathrm{D}_{4}$ & $\mathrm{D}_{5}$ \\
\hline Projectile [14][16] & -0.8 & 2.1 & -0.5 & 0 & 0.61 \\
\hline Target Plate [21] & -0.77 & 1.45 & -0.47 & 0 & 1.6 \\
\hline
\end{tabular}

Table 1: Material properties 
Since the simulations are done at room temperature, the temperature dependent parameters have no effect on the results. Piekutowski et al. [12] reported that the test specimens are nearly rate independent, so the rate effects are not included in the mesh density study. Hence, the $C$ and $D_{4}$ parameters are taken as zero. Their effect are investigated by introducing $C=0.002$ and $D 4=0.002$ $[14,15,18]$ to the reference mesh. The friction coefficient is taken as 0.61 . Additionally, by setting the value to zero, the effect of the friction coefficient is also investigated to account for the result dependence. Taking the target plate mesh settings $h=30, L=30, t=10$ in the core region as a reference, the rate effects and the friction coefficient effect are plotted in Figure 3.

The parametric study on mesh density, rate effects and friction coefficient showed that the highest effect is associated with the mesh density. The effects of the friction coefficient and the rate effects are less when compared to the mesh density. For the friction coefficient value of 0.61 used in the study, the ratio of the energy dissipated by friction to the initial energy of the bullet varies from $15 \%$ to $5 \%$ as the striking velocity changes from the lowest to the highest value. However, for the blade to casing impacts, this ratio is found to be in the order of $30 \%$, and this has a significant influence on containment requirements. The reason is the high frictional area at blade impact due to the change of the blade orientation while interacting with the casing. This is discussed in detail in later sections. The fully integrated element formulation (ELFORM=2) adds extra computational cost with respect to a constant stress formulation $(E L F O R M=1)$, however it does not require hourglass control and may allow use of a coarser mesh $[21,22]$. It is reported that in the fully integrated formulation (ELFORM=-2), the solid elements are prone to locking effects under bending especially for poor aspect ratios. To alleviate this problem, element formulations ELFORM=-1 and ELFORM=2 are recommended with the expense of computational cost. [22]. ELFORM=2 is observed to behave in the same way with the other fully integrated formulations which are used to mitigate the locking problem. These element formulations show the same convergence behaviour with the used formulation and at the reference mesh size the difference between the ELFORM=2 and these models is $6 \%$, with a $4 \%$ difference stabilizing after a $120 \%$ reference mesh size. 
The study on mesh density, rate effects, friction coefficient and the element formulation showed that the highest effect is associated with the mesh density. Although the agreement of the simulations with the experiment is subject to change with the effect of these parameters, which can shift the results apart from the measurements, the 'bullet to plate impact' simulations provided the necessary information to set up a 'blade to casing impact' methodology. Based on the observations from the impact experiment, the mesh density of the casing was adjusted to remove any meshrelated effects on the results.

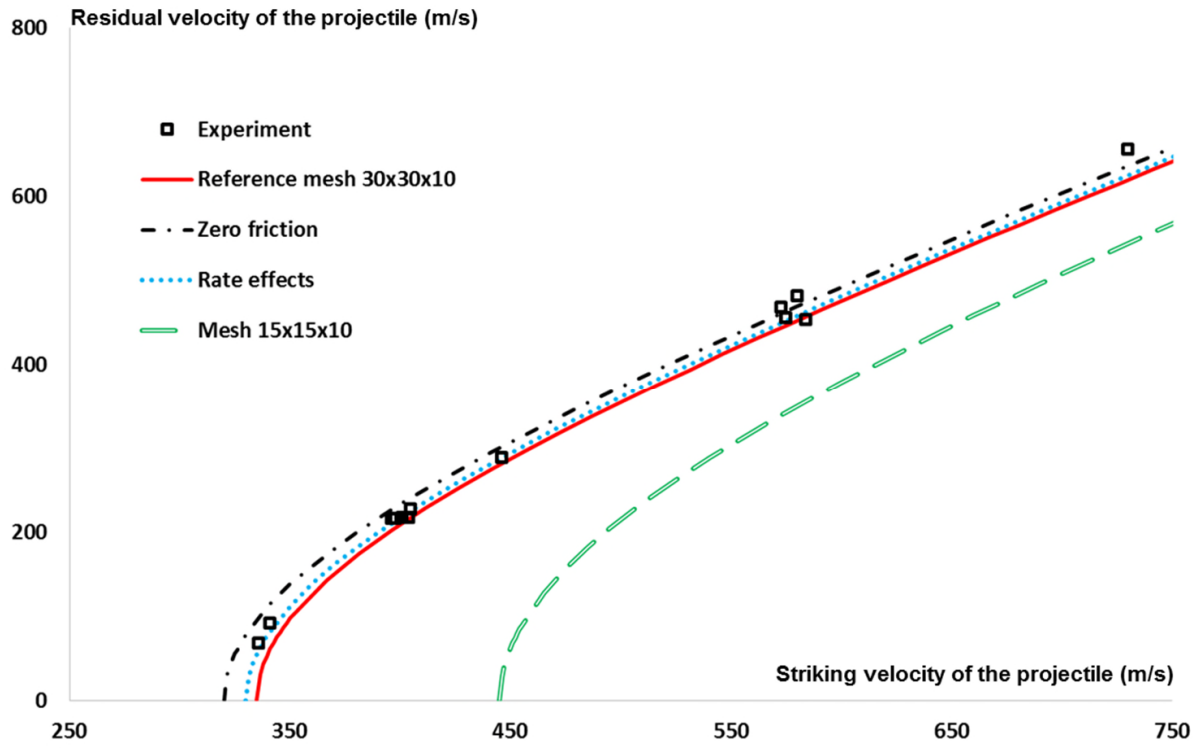

Figure 3. Simulation results compared against experiment

\section{MODELLING OF CASING AND BLADE TIP ARCHITECTURES}

The non-linear finite element software LS-DYNA has been commonly used in foreign and domestic object damage simulations in gas turbine applications. The LS-DYNA analysis methodology used in the bullet experiment is extended to model the blade release scenarios which include the rotor rotation and blade shedding. 


\subsection{Finite element model}

The whole 3D model of Figure 3 includes the blades and the bearing assembly which radially restrains the rotor. In this type of analysis, the turbine rotor is spun to a rotational speed for centrifugal loading. After the turbine reaches a certain speed, it is maintained at constant speed, and the blades are released afterwards. To make the parametric analysis computationally efficient, the whole model is replaced with a blades-only model by removing the disk and the bearing assembly. In the new blades-only model, an initial rotational speed is defined for the blades and their initial pre-stress state is ignored. The whole model is spun, kept at constant speed, and blades are released at time unit zero. Then blades impact the casing. At the blades only model, the blades are released with an initial rotational speed. The comparison shows that the kinetic energy evolutions of the blades are identical. Based on this observation, the parametric analysis is conducted with the assumption that the blades-only model will represent adequately the whole rotor model.



Figure 4. Evolution of the kinetic energy of blades over time for whole rotor and blades-only models 
The nickel-based superalloy Inconel 718 is assumed for the turbine rotor and the casing. The Johnson-Cook material model is used for the parts, and the material properties are taken from Erice et al. [23]. It is reported that the Johnson-Cook formulation provides reasonably good predictions in ballistics since it is able to capture the basics of the impact phenomena. However, the inclusion of the lode parameter improves the fidelity of the simulations especially in capturing the complex fracture patterns $[23,24]$. In the current study, the lode parameter dependence is not taken into account. The exclusion is not vital to identify the interdependencies in a blade to casing impact and to create design guidelines for an early design phase. However, for a detailed assessment of the containment approach, this parameter has to be included.

Thermal load of $1000 \mathrm{~K}$ is applied to the parts. The casing nodes at the downstream side are fixed and the upstream side is free to allow the casing to deform. A fixed aspect ratio below three is used in the perforation direction, and the effect of the circumferential mesh density of the casing on the results is investigated using 100,150, 200 and 300 elements. It has been found that the casing internal energy converges after 200 elements and the error between the 200 elements case and 300 elements case is around $0.3 \%$. The 100 elements case is $8 \%$ lower, and the 150 elements case is $3 \%$ lower with respect to the 200 elements case. Lower number of elements in the casing circumference results in a higher casing containment thickness. Then 200 elements are used in the study. Based on 200 elements at the casing circumference, the rotor mesh density at $70 \%$ of the reference mesh results in $4 \%$ higher casing internal energy and this drops to $2 \%$ for $80 \%$ of the reference mesh. The change in the casing internal energy stabilizes after $100 \%$ reference mesh.

\subsection{Sectoral and whole circumference blade release scenarios}

The following numbers of blades that simultaneously impact the casing are investigated: 1 blade, $3,5,15$ blades, half of the blades and all blades. A containment chart, which is the casing thickness required for containment, is generated. The region below a curve represents the conditions where the blades are not contained, and the upper region represents conditions where the blades are contained. The Model B containment thickness, straight blade tip impacting to $20^{\circ}$ 
inclined casing, is plotted as a function of the single blade kinetic energy and is shown in Figure 5a. The containment thickness is normalized with a random value which is approximately the casing thickness to contain five blades at nominal speed. Similarly to Figure 3, the kinetic energy of the impactor starts at a certain value to indicate the ballistic limit to penetrate the casing. At the same energy level, the required containment thickness increases with the increase in the number of the blades being released simultaneously. Another representation of the required containment thickness at different blade release speeds are plotted in Figure $5 \mathrm{~b}$. It is found that the containment requirement reaches a limit when the number of blades in a simultaneous multi-blade release reaches close to 15 .



Figure 5. Containment analyses of simultaneous release of all blades and a sector of blades

Since the blades have the same speeds, the force per blade is at the same order however during multi-blade impacts the cumulative effect of the blades that impact at a particular casing location result in a continuous straining at that region. If the straining reaches an upper limit, the casing shears and the upcoming projectiles perforate through the weakened or already sheared region. To capture the cumulative straining of multiple blades a case study using the same casing is done. At a lower rotational speed, the sectors of blades with different numbers are released to the same casing having a thickness which is capable of containing the blades in each case. The casing 
total displacement contour plots and the maximum casing displacement values are given in Figure $6 \mathrm{a}$ and Figure $6 \mathrm{~b}$ respectively. The casing displacement contour plots and the maximum casing displacement values are given in Figure $6 \mathrm{a}$ and Figure $6 \mathrm{~b}$ respectively. With the increase in the number of blades, the casing displacement reaches to a limit when the blade number gets close to 15 blades.

According to the observations given above, a sector having a large enough number of blades can result in the same effect that all blades would have in breaking the casing. For example, according to Figure 5a, a casing which is designed to contain three blades at nominal speed may require an additional $30 \%$ thickness to contain these three blades at an overspeed value. However, the casing may require additional $80 \%$ thickness to contain all of the blades, if blade shedding is to be used to prevent disk burst during a turbine overspeed. Equation (6) gives the expression that scales the thickness as a function of the blade number. Reference thickness is the value to contain one blade, and the reference blade count is 1 . Up to 5 blades $Y=1.0$ and $X=0.6$ and from 5 blades to 15 blades $Y=0.9$ and $X=0.47$. Once the single blade thickness requirement is computed, the reference thickness value can be scaled for different blade numbers. The required thickness becomes constant with 15 blades.

The above condition applies to a solid casing. Of course with the inclusion of stiffeners [5] or with different casing architectures the required containment thickness can be kept at moderate levels. The next section investigates the effect of casing inclination with a view towards reducing the casing thickness requirement for blade shedding applications. 




1 blade

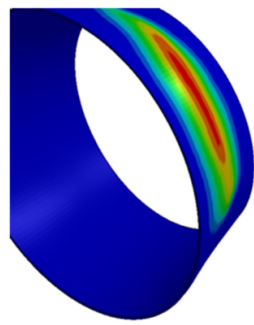

15 blades

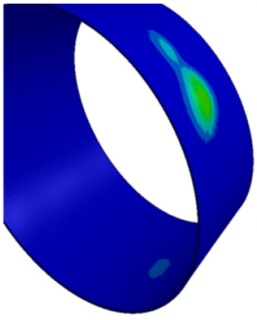

3 blades

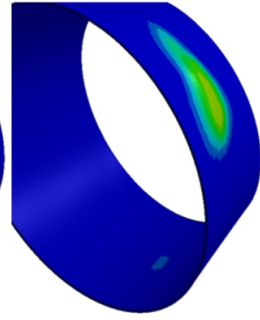

5 blades

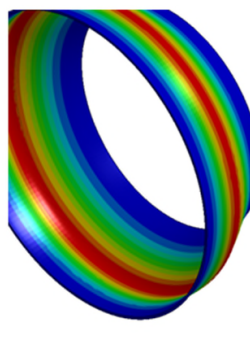

All blades

Max. displacemen

1.00 (Normalized)

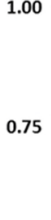

0.50



0.00

0.75

0.25

0.00

モMax. displacement

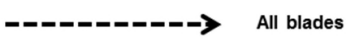

Figure 6. Casing displacement contours and evolution of max. casing displacement at the impact region

$$
\mathrm{t}_{\text {new }}=\mathrm{t}_{\text {ref }} \cdot\left[\mathrm{Y}+\mathrm{X} \cdot \ln \left(\frac{\text { blade }_{\text {blade }}}{\text { bl, ref }}\right)\right]
$$

\subsection{Effect of casing inclination}

This section aims to investigate the effect of the casing orientation by three casing inclinations which are $0^{\circ}, 20^{\circ}$ and $40^{\circ}$ in Model A, Model B and Model C respectively. For the contained and uncontained scenarios, the event sequence of the blade impact to the casing is sketched in Figure 7. Just after the release of the blades (Figure 7a), the blade tips hit the casing (Figure 7b), and they start to deform with the casing. With this impact, the blades lose their orientation and a long blade section including the blade root hits the casing. In the case of less energy, the blades are contained (Figure 7c), and they ricochet off the casing (Figure 7d). If the blades have excess energy, the casing cracks (Figure 7e) and the blades perforate the casing at the next stage (Figure 7f). So the magnitude of rebound is governed by the casing angle. 

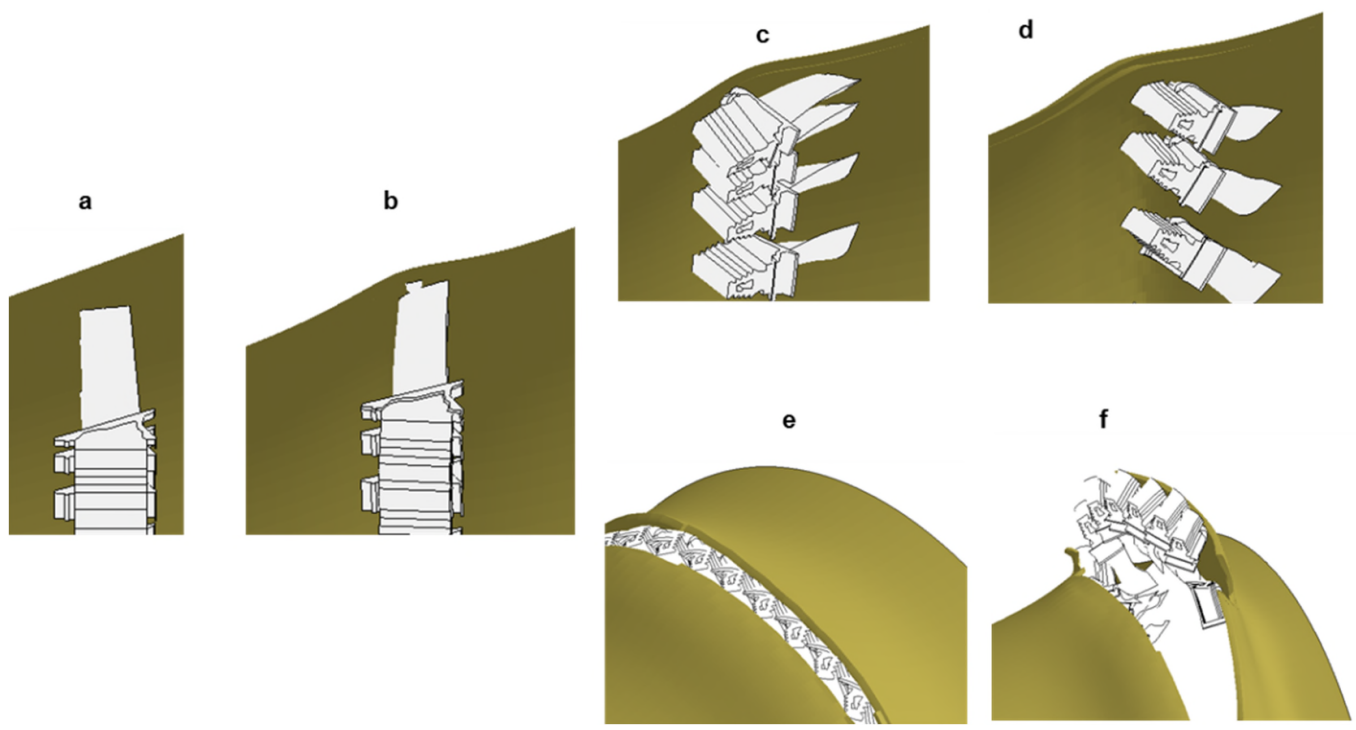

Figure 7. Event sequence for contained and uncontained conditions

For the straight casing, the force in the axial direction is less than the others since the total casing reaction has an axial component while blades ricochet off the inclined casings (Figure 8a). The event sequence described in Figure 7a can also be monitored with the resultant forces. After the blade release the highest resultant force is seen for the straight casing at time unit 0.1 . In the inclined configurations, the resultant force is less, since the blades lose their orientation and slide along the casing. This is the instant (Figure 7b) just after the impact. The second peak in the resultant force happens with the impact of the long blade surface including the blade root. This is the instant sketched in Figure 7c and Figure 7e and happens at 0.4 time units, for inclined casings, and at 0.6 time units for the straight casing. After the second peak in resultant force, blades either perforate and lose the contact, or remain contained to slide along the casing. In the given plot the blades are contained, and they continuously lose their energy while sliding along the casing. 


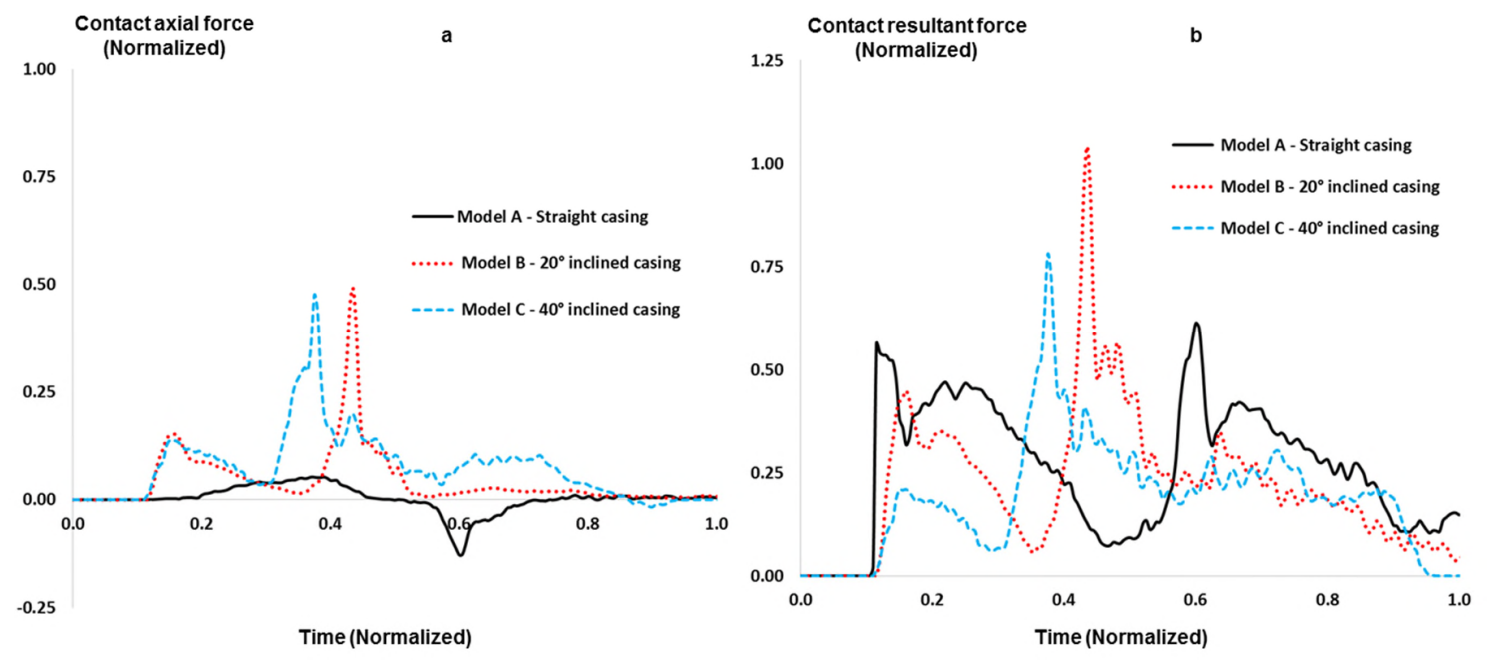

Figure 8. Impact axial force pushing the blade in the gas stream direction and impact resultant force

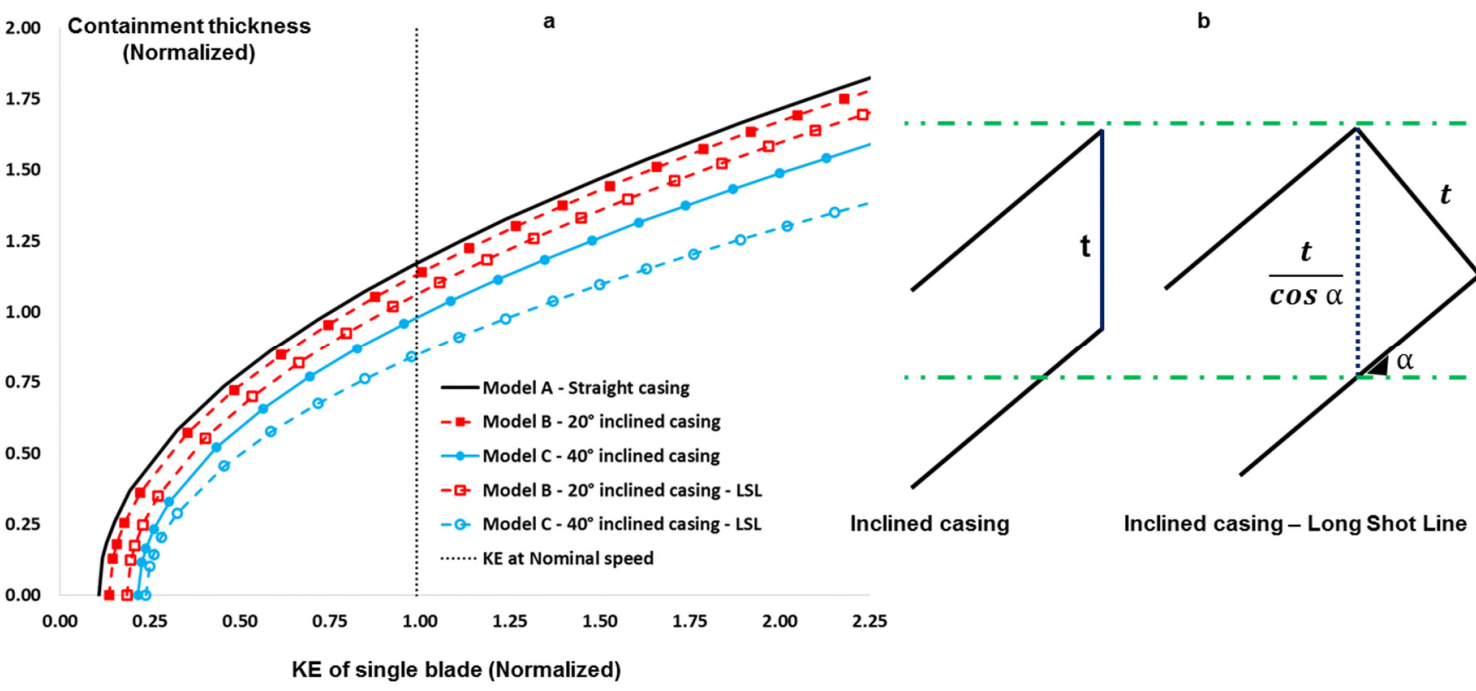

Figure 9. Effect of casing orientation on containment thickness

The containment charts of the three casing configurations are plotted in Figure 9a. With the increase in the casing inclination the containment requirement decreases. The blade energy is also consumed with the side impact. Additionally, the effect of long shot line distance (LSL) has to be mentioned. This effect is sketched in Figure 9b. A casing having a thickness $t$ in the vertical 
direction will have a higher shot line thickness if it is obtained by rotating a straight casing (thickness of t) around its centreline. For example, $40^{\circ}$ inclined Model B thickness $t$ will become $1.305^{\star} t$ for LSL case to result in further reductions in the containment requirement.

Equation (7) scales the thickness requirement of Model A with a straight blade according to the casing inclination. For casings with a long shot line distance, the $V$ parameter is 1.0 , and it is 0.7 for the inclined casings which have the thickness " $\mathrm{t}$ " in the perforation direction.

$$
t_{\text {new }}=t_{\text {ref }} \cdot \cos (V \cdot \alpha)
$$

According to the above, 100 units of casing thickness requirement will reduce to 88 units for a $40^{\circ}$ angle. This is the pure effect of the inclination. For the LSL case, the reduced value will be 76 units due to the additional thickness in the vertical direction. For the $20^{\circ}$ casing these values become 97 and 94 units respectively.

\subsection{Effect of blade tip geometry and friction coefficient}

The effect of tip geometry on containment requirements is investigated with the comparison between three blade tip architectures. These are Model B, Model D and Model E, which impact the $20^{\circ}$ inclined casing. If the blades are assumed to be designed for the same aerodynamic target, they will eventually have differences. A shrouded blade should be expected to be heavier than an unshrouded blade, and the increased mass will require higher containment thickness for a specific energy level. However, in this study, the investigated blades are adjusted so that the difference in their mass and position of the gravity centre are minimal. As mentioned in the event sequence, blades lose their orientation, and the highest impact force appears in the third step (Figure $7 \mathrm{c}$ and 7e) which is mostly related to the effect of the blade root. Due to the change in the orientation of the projectile, the containment requirement between these configurations having the same mass is found to be identical. The resultant impact force is given in Figure 10a. Due to its inclined tip, Model 
$D$ reaches the casing first. The Model $B$ with the straight blade reaches the casing slightly later. Since the shrouded geometry is the shorter blade to achieve mass equivalence among the three configurations, it impacts the casing last. The time evolution of the resultant force is very similar among the three configurations, and the similarity can also be seen in their containment requirement which is plotted in Figure 10b.

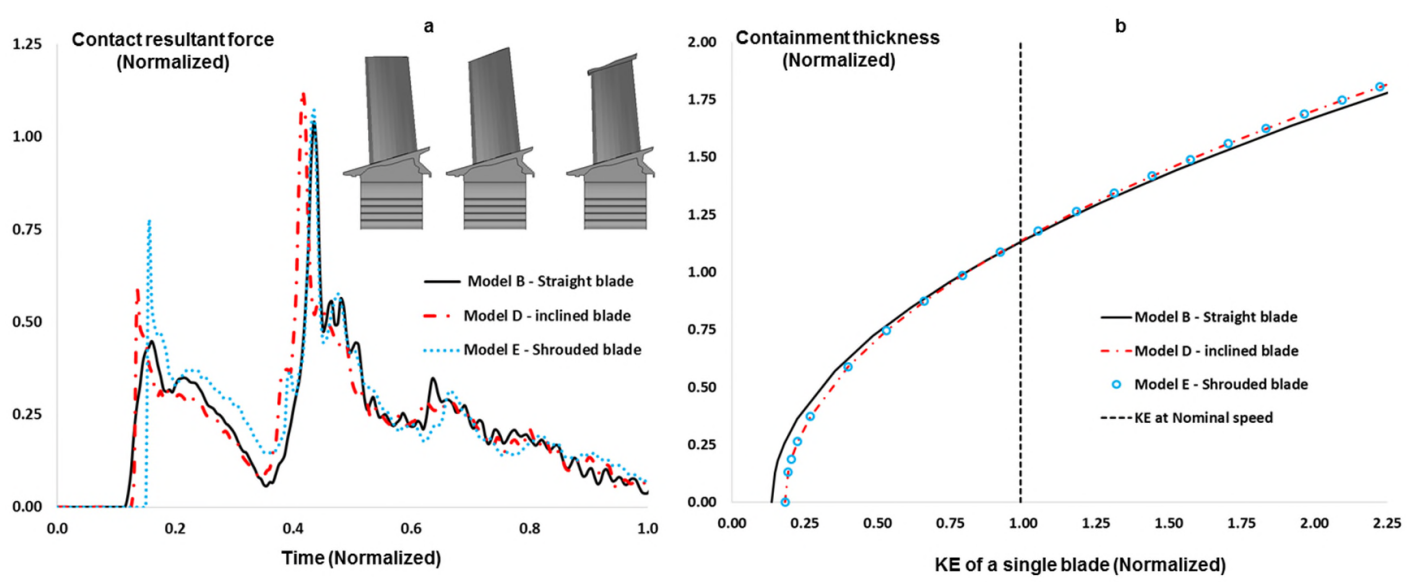

Figure 10. Impact forces and energy levels after impact for different blade tip configurations

The kinetic energy is dissipated by the sliding friction as the blades slide on the inner face of the containment ring. He and Xuan et al. [25] provided a list of friction coefficients from literature ranging from 0.01 to 0.57 considering ballistic impacts involving metal to metal contacts, metal working conditions and non-ideal projectile impacts. In our study, the reference friction coefficient is 0.05 and a parametric analysis is carried out to investigate the effect by changing the value from frictionless contact to 0.5 . The effect of the friction coefficient on containment for Model B, is plotted in Figure 11a. Equation (8) gives the correction for a containment curve for different friction coefficients. In the equation, reference thickness is for Model B and the reference friction coefficient is 0.05 . Like the casing inclination, the friction coefficient has a significant effect on the containment requirement. When compared in Figure 9, the Model B containment line, shifts towards the Model C $40^{\circ}$ LSL line. In case of frictionless impact, the same line shifts slightly above the Model A line. The 
amount of energy dissipated as a fraction of the total energy is plotted in Figure 11b. The values are the average values of each containment curve. The energy dissipated by friction increase up to $40 \%$ of the total energy as the friction value reaches 0.5 . The blade and casing energies decreases and the percentage of eroded elements increase with the increase in friction coefficient.

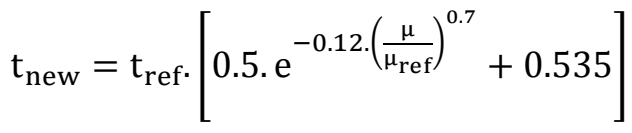

Mickelsen et al. [26] stated that the low friction coefficients in smooth fiber surfaces in fan containment systems exhibit poor performance in energy dissipation of the impacting blades, and this condition requires more containment structure increasing the total mass of the containment system. They proposed an upper layer including a shear thickening non-Newtonian fluid which also penetrates into the lower ballistic layer for Honeywell engines. The presence of fluid provides flexibility in installation. The ballistic layer and fluid system exhibit more viscous behaviour, even rigid, to dissipate energy at high deformations during an impact. The proposed method is a practical way of increasing the frictional dissipation, as well as weight saving. However, in an engine hot section application, the viscosity of the fluid may decrease with temperature. 

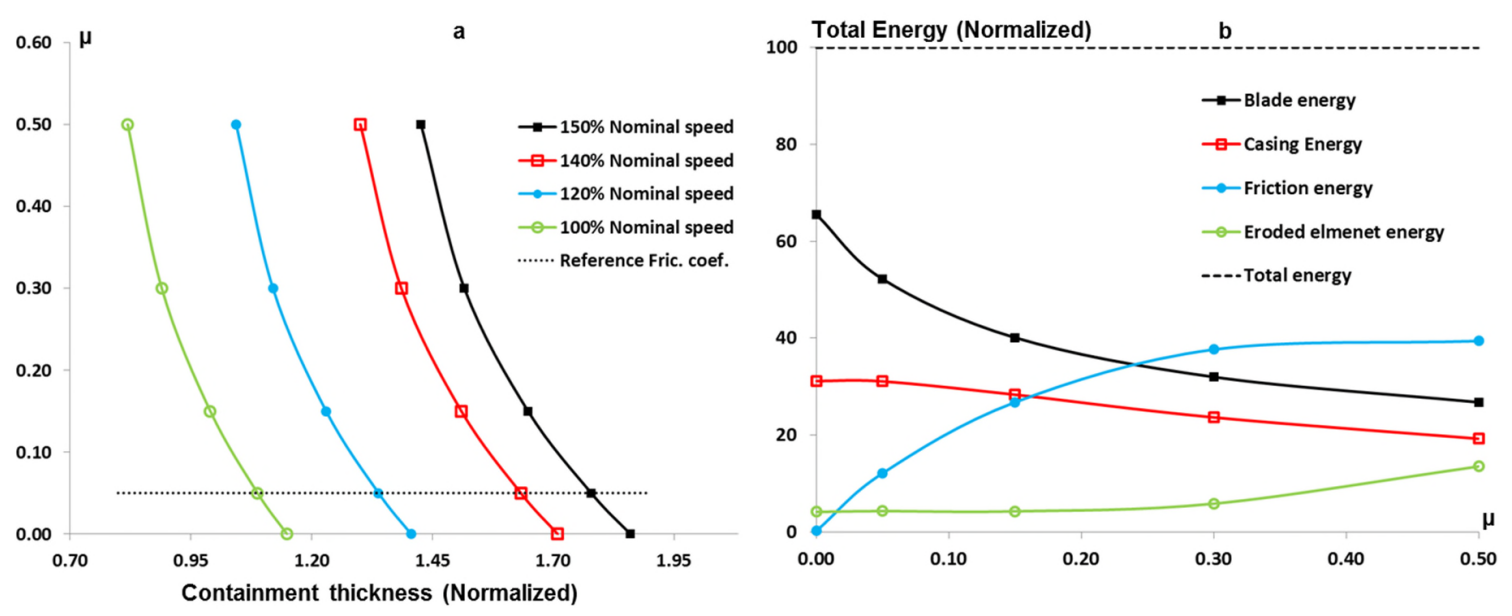

Figure 11. Change in containment requirement as a function of the blade release speed and the friction coefficient

\section{OVERSPEED and DESIGN CONSIDERATIONS}

Engine manufacturers try to avoid hazardous outcomes after a failure event. Loss of a blade sector may trigger violent vibrations in the rotor subsystems which may trigger secondary failures in the engine, i.e. an unbalance-related rubbing between two shafts to trigger the failure of another spool due to localized heating. Loss of a blade sector can trigger sequential loss of the remaining blades. The loads related to the sequential loss can also be transferred to the airframe to cause additional failures. The intention in overspeed protection is to release all the blades at the same time which minimizes the occurrence of an unbalanced motion.

This section discusses the application of a simultaneous blade release for overspeed prevention by use of an overspeed trajectory of a turbine after a shaft failure. The overspeed analysis is based on the methodology described by Eryilmaz and Pachidis [27]. Turbine performance parameters, such as the total pressure evolution in front of the turbine stage, are calculated from an experimental high power surge case. Then the end load acting on the turbine is used to calculate the friction which is generated when the unlocated turbine stage reaches and impacts the stationary structures behind. 


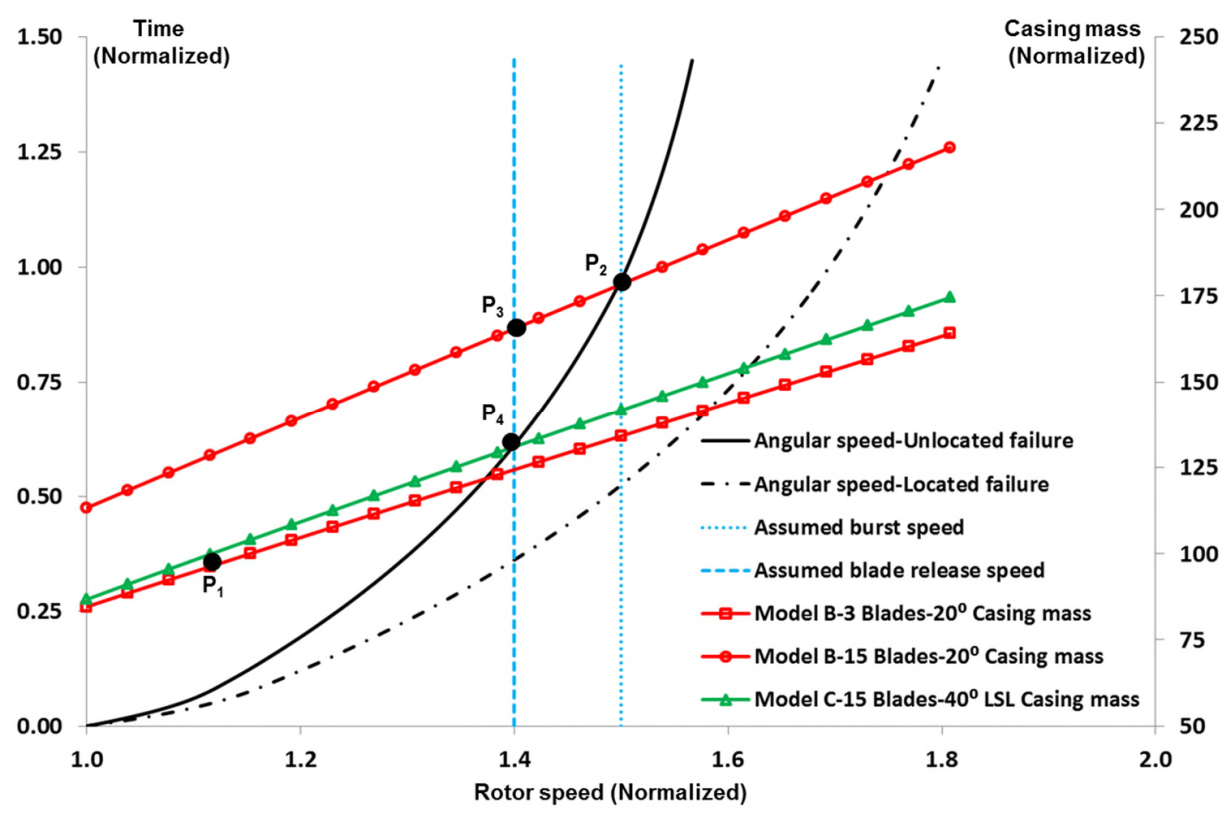

Figure 12. Overspeed design space for blade shedding as an overspeed control

An overspeed design space for a blade shedding application is given in Figure 12. The horizontal axis is the rotor acceleration track after the shaft failure. The primary vertical axis (left axis) is the time, and the right secondary axis is the thickness required for the blade containment. In the unlocated overspeed track, given by the full black line, there is friction between the rotor and the stationary structures acting against acceleration. The centre-lined black line gives the overspeed track without the presence of contact friction. This is the case which is seen in located failures where the bearing arrangement does not allow rotor movement.

The $20^{\circ}$ inclined casing of Model $B$ is designed to contain three blades at $115 \%$ nominal speed and requires a mass of $100 \%$ (Point $\mathrm{P}_{1}$ ). The assumed rotor burst line, which is positioned at a lower value to make the shedding necessary, stands at 150\% nominal speed (Point $P_{2}$ ). To secure the disk from bursting, the blades are to be designed to be released at $140 \%$ speed. In this condition, the casing which is capable of containing three blades at $115 \%$ speed (Point $\left.\mathrm{P}_{1}\right)$ needs additional mass of about $178 \%$ to contain all blades (Point $\mathrm{P}_{3}$ ). By adding more inclination to the 
casing, the mass requirement can be traded off. The $40^{\circ}$ inclined casing of Model $\mathrm{C}$, with the long shot line will need a thickness of $145 \%$ and recovers $22 \%$ of the mass (Point $\mathrm{P}_{4}$ ). The difference between a located and unlocated failure is the time duration which the rotor takes to reach from $140 \%$ speed to $150 \%$. Since this is shorter for the located case, to secure the shedding, it will be necessary to release the blades at a lower speed. This will require less thickness. However, it will be harder to release the blades because the rotational speed will not allow enough plastic growth if the shedding relies on the disc growth. Alternatively, it will require a higher stress concentration on the blade if the shedding relies on an overspeed notch.

As mentioned in the above paragraph, the mass increase to contain all the blades can be recovered by use of an inclined architecture. With the advances in manufacturing techniques, use of smart materials can also result in the reduction of the mass. Auxetic materials exhibit negative Poisson's ratio which means they get thicker when they are stretched. A fan casing with auxetic ballistic liner is proposed by Webb [28]. It is reported that the thickening effect will increase the impact effectiveness of a blade out condition and the low density of the material will result in further weight reductions. As an application in the hot section of the engine, Schmidt et al. [29] studied an auxetic casing for tip clearance control under a modern high-pressure compressor loading conditions during a flight mission. Temperatures up to $873 \mathrm{~K}$ were applied to the structures to monitor the expansions. Although the study did not touch the stress and fatigue behaviour, the application of this smart material is promising to be used in the turbine section for containment.

\section{SUMMARY and CONCLUSIONS}

The objective of this research is to study the effects of different blade tip geometries and casing inclinations on containment to understand the impact mechanism and to find a configuration providing improvements in containment capacity.

It has been shown that the thickness requirement to contain simultaneously released blades increases with blade number. Beyond a certain number of blades, no additional casing thickness is needed. A sector having enough number of blades, in our case 15 , can cause the same effect with 
all the blades being released. Even the casing type, blade mass and other boundary conditions are kept to be the same, this number may change as a function of the radius, blade solidity and overall number of blades. A future application of the current study for intermediate and low pressure turbines or for different high pressure turbines will be helpful to capture a general expression for the critical blade number as a function of the overall blade number.

The effect of the blade tip geometry is found to be less when compared to the effect of the casing inclination. It has been demonstrated that with the increase in casing angle, the containment requirement reduces. Therefore, it is essential during the design phase to consider this point and investigate the feasibility of implementing an inclined containment shield above the turbine casing as a back-up protection system. An inclined containment shield may provide on one hand a better containment capacity than a straight structure for a given thickness, and on the other hand, it may help reduce the mass of the assembly.

- Since the strongest impact results from the blade root, it is possible to put an inclined structure above a straight ballistic liner to benefit from the angle effect.

- The controlled blade release speed has to be increased to secure the effect of plastic disk growth and to have less stressed overspeed notch.

- Located failures without the presence of axial friction have a steeper overspeed track, and they may require an earlier release speed when compared to unlocated failures.

Within the scope of this study, several simplifications have been made in the geometry, material properties and the boundary conditions. For a detailed assessment several areas have to be considered in detail. These can be listed as;

- The casing geometry is straight, however in a real geometry the casing is shorter and may have segmented seal features to dissipate some of the blade kinetic energy. Additionally, for tip 
clearance and axial movement control, these segments may be assembled within joints, i.e. a bird mouth and/or a spigot, which gives them flexibility in the radial and axial directions.

- A single rotor stage is used and this fits to high-pressure and intermediate-pressure turbine geometries. However, there are also turbine stages in which the guide vanes are placed closed to the rotor row. After the initial impact, the rotors may interfere with these stators to change the impact orientation and the impact energy.

- Material strength changes as a function of the ductile damage and also as a function of plastic heating. The fan-blade off simulations does not require the plastic heating due to the low temperatures. However, turbines operate in a harsh environment and any increase in the temperature results in significant changes in the material strength.

- In the current study a thermal load is applied to the parts. In a real case, additional to the plastic heating, a considerable amount of frictional heating may be present as a function of the applied friction coefficients. To capture these effects, a thermal and structural coupled solution is necessary.

- The strength and impact behaviour of the turbine materials (i.e. nickel alloys or ceramic matrix composites) have to be characterised specifically for the above mentioned conditions to verify the methodologies used for turbine to casing impacts.

\section{ACKNOWLEDGEMENTS}

The authors would like to express their gratitude to Rolls-Royce plc for supporting this research and permission to publish the paper.

\section{REFERENCES}

[1] LANE, A.D. (1989), Development of an Advanced Fan Blade Containment System, DOT/FAA/CT-89/20, FAA Technical Centre, Phoenix, Arizona 
[2] DEWHURST, T., B., (1991), The impact load on containment rings during a multiple blade shed in aircraft gas turbine engines, 91-GT-163, International Gas Turbine and Aeroengine Congress and Exposition, Orlando. doi:10.1115/91-GT-163

[3] HE, Q., XUAN, H., LIU, L., HONG, W., WU, R. (2013), Perforation of aero-engine fan casing by a single rotating blade. Aerospace Science and Technology. 25, pp236-241

[4] KRAUS, A., FRISCHBIER, J., (2002), Containment and penetration simulation in case of blade loss in a low pressure turbine, DYNAmore LS-DYNA Forum, Bad Mergentheim.

[5] HERMOSILLA, U., ALCARAZ, J. L., AJA, A. M., (2004), Blade impact simulation against turbine casings, ABAQUS user's conference.

[6] CARNEY, K., S., PEREIRA, J., M., REVILOCK, D., M., MATHENY, P., (2009), Jet engine fan blade containment using an alternate geometry, International Journal of Impact Engineering, 36, pp 720-728.

[7] SEINTURIER, E., (2010), The technical challenge for green affordable turboshaft engine, European Rotorcraft Forum

[8] SOUPIZON, J., (2006), Device for limiting turbine overspeed in a turbomachine, US Patent 20060251506 A1

[9] ADAMS, P. R., MAGGE, S. S., STAUBACH, J. B., LORD, W. K. and SCHWARZ, F. M., (2014), Turbine section of high bypasses turbofan, US Patent 8850793 B2.

[10] STEC, P. F., DEMERS, D. E. and SCHMIDT, R. L., (2006), Turbine blade with recessed squealer tip and shelf, US Patent US 6991430.

[11] HAGG, A, SANKEY, G., (1974) 'Perforation of aluminium plates with ogive-nose steel rods at normal and oblique impacts', Journal of Engineering for Power, 96 (2), pp. 114-123. 
[12] PIEKUTOWSKI, A. J., FORRESTAL, M. J., POORMON, K. L., WARREN, T. L., (1996) 'Perforation of aluminium plates with ogive-nose steel rods at normal and oblique impacts', International Journal of Impact Engineering, 18, pp. 877-887.

[13] JOHNSON, G., COOK, W., (1985), Fracture characteristics of three metals subjected to various strains, strain rates temperatures and pressures, Engineering Fracture Mechanics, 21(1), pp. 31-48. https://doi.org/10.1016/0013-7944(85)90052-9

[14] GRAY III, G., T., CHEN, S., R., WRIGHT, W., LOPEZ, M. F., (1994), Constitutive equations for annealed metals under compression at high strain rates and high temperatures, LA-12669-MS, Los Alamos National Laboratory, US.

[15] MAUDLIN, P. J., STOUT, M. G., (1996), Metal cutting simulation of 4340 Steel using an accurate mechanical description of material strength and fracture, LA-UR-96, Los Alamos National Laboratory, US. digital.library.unt.edu/ark:/67531/metadc680908/

[16] SELI, H., AWANG, M., ISMAIL, A. I., RACHMAN, E., AHMAD, Z. A., (2013), Evaluation of Properties and FEM Model of the Friction Welded Mild Steel-Al6061 Alumina, Materials Research, 16(2), pp. 453-467.

[17] MANES, A., PERONI, L., SCAPIN, M., GIGLIO, M., (2011), Analysis of strain rate behaviour of an Al 6061 T6 alloy, Procedia Engineering, 16, pp. 3477-3482.

[18] ABIDI-SEDEH, A. H., MADHAVAN, V., BAHR, B., (2003), Extension of Oxley's Analysis of Machining to Use Different Material Models, ASME Journal of Manufacturing Science and Engineering, 125(4), pp. 656-666.

[19] ELSEN, A., LUDWIG, M., SCHAEFER, R., GROCHE, P., (2010), Fundamentals of EMPTWelding, 4th International Conference on High Speed Forming, Ohio, USA.

[20] LESUER, D. R., KAY, G. J., LeBLANC, M. M., (2001), Modeling large-strain, high-rate deformation in metals, UCRL-JC-134118, Lawrence Livermore National Laboratory, US. 
[21] LS-DYNA Aerospace Working Group (2013), Modelling Guidelines Document, Version 13.1

[22] Erhart, T., (2011), Review of Solid Element Formulations in LS-DYNA-Properties, Limits, Advantages, Disadvantages, LS-DYNA Forum, Stuttgart

[23] ERICE, B., PEREZ-MARTIN, M. J., GALVEZ, F., (2014) 'An experimental and numerical study of ductile failure under quasi-static and impact loading of Inconel 718 nickel-base superalloy', International Journal of Impact Engineering, 69, pp. 11-24.

[24] Chocron, S., Erice, B., Anderson, C., (2011), A new plasticity and failure model for ballistic application, International Journal of Impact Engineering, 38, pp. 755-764.

[25] HE, Q., XUAN, H., LIAO, L., HONG, W., WU, R. (2012), Simulation methodology development for rotating blade containment analysis. Journal of Zhejiang University-SCIENCE A (Applied Physics \& Engineering). 13(4), pp. 239-259. https://doi.org/10.1631/jzus.A1100294

[26] MICKELSEN J. C., DODDMAN, W. H., WATSON, B., (2012), Fan containment systems with improved impact structures, US 20120099976 A1

[27] ERYILMAZ, I., PACHIDIS, V.,(2017), Turbine thermomechanical modelling during excessive axial movement and overspeed, International Society of Air Breathing Engines Conference, ISABE2017-21440, Manchester, UK

[28] WEBB, W., (2015), Fan case with auxetic liner, US 20150345320 A1.

[29] SCHMIDT, T., EISENMANN, S., VELIKOV, V., GUMMER, V., HUPFER, A., (2017), Analysis of an auxetic casing structure for tip clearance control under various temperature and pressure conditions, International Society of Air Breathing Engines Conference, ISABE- 2017-22629, Manchester, UK 
2019-02-25

\section{Multi-blade shedding in turbines with different casing and blade tip architectures}

Eryilmaz, Ibrahim

Elsevier

Eryilmaz I, Guenchi B, Pachidis V. (2019) Multi-blade shedding in turbines with different casing and blade tip architectures. Aerospace Science and Technology, Volume 87, April 2019, pp. 300-310 https://doi.org/10.1016/j.ast.2019.02.025

Downloaded from Cranfield Library Services E-Repository 